\title{
Inhibition of human $\mu$-calpain by conformationally constrained calpastatin peptides
}

\author{
José Pfizer'1, Irmgard Assfalg-Machleidt², \\ Werner Machleidt ${ }^{3}$ and Norbert Schaschke ${ }^{4, *}$ \\ ${ }^{1}$ Max-Planck-Institut für Biochemie, Am Klopferspitz 18, \\ D-82152 Martinsried, Germany \\ ${ }^{2}$ Abteilung für Klinische Chemie und Klinische \\ Biochemie, Chirurgische Klinik, Ludwig-Maximilians- \\ Universität München, Nußbaumstr. 20, D-80336 \\ München, Germany \\ ${ }^{3}$ Adolf-Butenandt-Institut, Ludwig-Maximilians- \\ Universität München, Schillerstr. 42, D-80336 München, \\ Germany \\ ${ }^{4}$ Fakultät für Chemie, Universität Bielefeld, \\ Universitätsstr. 25, D-33615 Bielefeld, Germany \\ *Corresponding author \\ e-mail: norbert.schaschke@uni-bielefeld.de
}

\begin{abstract}
The 27-mer peptide CP1B-[1-27] derived from exon 1B of calpastatin stands out among the known inhibitors for $\mu$ - and $\mathrm{m}$-calpain due to its high potency and selectivity. By systematical truncation, a 20-mer peptide, CP1B[4-23], was identified as the core sequence required to maintain the affinity/selectivity profile of CP1B-[1-27]. Starting with this peptide, the turn-like region Glu $^{10}(\mathrm{i})$ Leu $^{11}(i+1)-$ Gly $^{12}(i+2)-$ Lys $^{13}(i+3)$ was investigated. Sequence alignment of subdomains $1 \mathrm{~B}, 2 \mathrm{~B}, 3 \mathrm{~B}$ and $4 \mathrm{~B}$ from different mammalians revealed that the amino acid residues in position $\mathrm{i}+1$ and $\mathrm{i}+2$ are almost invariably flanked by oppositely charged residues, pointing towards a turn-like conformation stabilized by salt bridge/H-bond interaction. Accordingly, using different combinations of acidic and basic residues in position $\mathrm{i}$ and $\mathrm{i}+3$, a series of conformationally constrained variants of CP1B-[4-23] were synthesized by macrolactamization utilizing the side chain functionalities of these residues. With the combination of $\mathrm{Glu}(\mathrm{i}) / \mathrm{Dab}(\mathrm{i}+3)$, the maximum of conformational rigidity without substantial loss in affinity/selectivity was reached. These results clearly demonstrate that the linear peptide chain corresponding to subdomain $1 \mathrm{~B}$ reverses its direction in the region Glu $^{10}-$ Lys $^{13}$ upon binding to $\mu$-calpain, and thereby adopts a loop-like rather than a tight turn conformation at this site.
\end{abstract}

Keywords: cysteine protease; macrolactamization; peptidomimetic; protease inhibitor.

\section{Introduction}

The calpains constitute a family of calcium-dependent cysteine proteases (clan CA, family C2) (Barrett et al., 1998). Among them, the ubiquitous mammalian calpains, $\mathrm{m}$-calpain and $\mu$-calpain, are by far the best-character- ized members of this family. Both enzymes exhibit their catalytic activity in the cytosol at neutral $\mathrm{pH} . \mu$-Calpain reaches its half-maximal activity at calcium concentrations in the micromolar range, whereas $\mathrm{m}$-calpain needs millimolar calcium concentrations to be active. The ubiquitous calpains are heterodimeric proteins composed of a large subunit of approximately $80 \mathrm{kDa}$ harboring the catalytic activity and a small $28-\mathrm{kDa}$ subunit proposed to exhibit regulatory activities. Whereas the small subunit is identical for both enzymes, the large subunits share $55-65 \%$ sequence homology between the two proteases (for recent reviews see Sorimachi and Suzuki, 2001; Goll et al., 2003). The X-ray structures of calcium-free rat and human $\mathrm{m}$-calpain have elucidated the structural organization of the enzyme (Hosfield et al., 1999; Strobl et al., 2000). In particular, the large subunit is composed of six domains. Two of them (domain Ila and IIb) constitute the catalytic core with an overall papain-like fold.

Besides the local calcium concentration, the endogenous protein-type inhibitor calpastatin plays an important role in the regulation of calpain activity (for a recent review see Wendt et al., 2004). Calpastatin is widely distributed in mammalian tissues. Upon calcium activation, calpastatin specifically binds to the calpains in a reversible fashion. Calpastatin comprises five domains: an $\mathrm{N}$-terminal, so-called L-domain without inhibitory activity and four repetitive inhibitory domains (1-4), each of them organized in three subdomains (A, B and C). Only subdomain $B$ is able to block the catalytic activity of calpain, whereas peptides representing subdomains $A$ and C activate calpain in vitro (Tompa et al., 2002) and in the cell (Bánóczi et al., 2007). Subdomains $A$ and $C$ have been shown to bind to domain IV of the large and domain $\mathrm{VI}$ of the small subunit of calpain, respectively (Takano et al., 1995), subdomain B is proposed to interact with an area near the active site (domain Ila and/or Ilb).

In the last decade, several attempts have been undertaken to obtain a detailed picture of the interaction mode of calpastatin with calpain at the atomic level. Of particular interest in this context is the bound conformation of the 27-mer peptide, CP1B-[1-27] (compound 1; see Figure $1 \mathrm{~A}$ ), derived from subdomain $1 \mathrm{~B}$ of human calpastatin, because this peptide inhibits calpain almost as efficiently as the parent whole inhibitory domain 1 of the protein (Maki et al., 1989). Amongst the synthetic calpain inhibitors that have been developed so far (for reviews see Wells and Bihovsky, 1998; Donkor, 2000), CP1B[1-27] (1) stands out due to its unequaled affinity/selectivity profile. Consequently, these unique properties have been utilized in cell biological studies. By conjugation with penetratin, a cell-permeable variant of CP1B-[1-27] (1) was obtained that is ideally suited as a tool to study the (patho)physiological roles of the ubiquitous calpains (Gil-Parrado et al., 2003). For now, investigations of domain 1 of human (Uemori et al., 1990) and porcine 
A

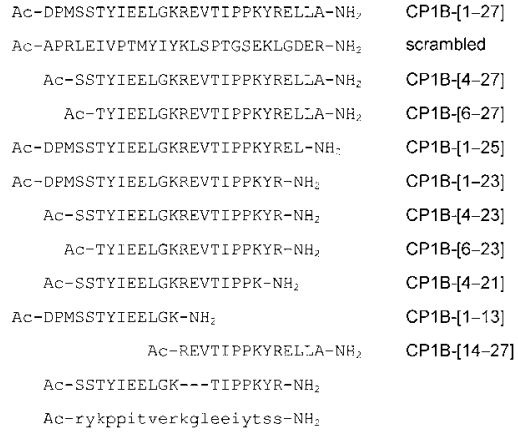

B

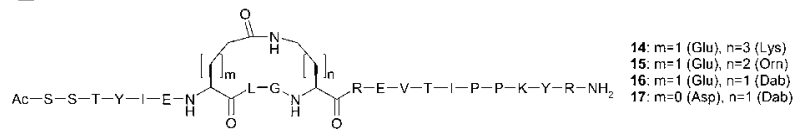

Figure 1 Structure of linear (A) and conformationally constrained (B) calpastatin peptides.

Peptide 12: '---' represents 8-amino-3,6-dioxaoctanoic acid replacing the tripeptide portion $\mathrm{Arg}^{14}$-Glu ${ }^{15}$-Vall ${ }^{16}$ spatially; peptide 13: the lower case letters indicate the corresponding D-amino acids.

(Konno et al., 1997) calpastatin in aqueous solution both by ${ }^{1} \mathrm{H}-\mathrm{NMR}$ and $\mathrm{CD}$ spectroscopy have revealed that the protein is highly flexible and has no well-defined 3D structure. Thus, calpastatin has been classified as a member of the group of 'intrinsically unstructured proteins' (Tompa, 2002; Uversky, 2002). Consequently, further efforts to obtain structural data of an inhibitory domain of calpastatin addressed the calpain-bound state of the protein. CD studies with peptides derived from subdomain $A$ and $C$ point to a $\alpha$-helical conformation for both peptides (Mucsi et al., 2003). Subsequently, the X-ray structure of a 19-mer domain 1C peptide of calpastatin in complex with domain $\mathrm{VI}$ of calpain has revealed a $\alpha$-helical conformation and confirmed the CD studies (Todd et al., 2003). Based on this structure, a homology model of the complex of a 19-mer domain $1 \mathrm{~A}$ peptide of calpastatin and domain IV of calpain has been built and also supports an $\alpha$-helical conformation (Todd et al., 2003). However, until now, no X-ray data are available for calpain-bound subdomain B. NMR studies in DMSO, which is expected to mimic a structure-inducing environment, have shown that the residues Glu $^{10}-$ Leu $^{11}$ Gly $^{12}$-Lys ${ }^{13}$ and Pro ${ }^{20}-$ Lys $^{21}-$ Tyr $^{22}-$ Arg $^{23}$ of CP1B-[1-27] (1) adopt a turn-like conformation. However, regular structural elements, such as an $\alpha$-helix or a $\beta$-sheet, have not been identified (Ishima et al., 1991). The importance of the amino acid residues Leu ${ }^{11}$ and Gly ${ }^{12}$ for the inhibitory activity of CP1B-[1-27] (1) has been confirmed by a combination of a $\beta$-alanine/alanine scan (Betts et al., 2003). Additionally, the residues $\mathrm{Thr}^{17}, \mathrm{Ile}^{18}$ and $\mathrm{Pro}^{19}$ have been identified to strongly contribute to the inhibitory activity of CP1B-[1-27] (1) (Betts et al., 2003). N-terminally and C-terminally truncated variants of CP1B-[1-27] (1) have revealed that almost the complete sequence is necessary to maintain the inhibitory potency (Betts and Anagli, 2004).

From these SAR data obtained so far, describing the influence of linear modifications within the sequence of CP1B-[1-27] (1), only little information could be derived about the 3D architecture in the bound state. To reduce the conformational space of a linear peptide sequence, a typical approach is to synthesize cyclic versions of the interesting sequence portions by macrolactamization. In particular, those portions supposed to be part of turns are of greatest interest. However, in the case of a long peptide as the 27-mer CP1B-[1-27] (1), it is generally difficult to identify suitable sites within the sequence for macrolactamization. Our attention was attracted by the sequence portion Glu $^{10}$-Leu ${ }^{11}-$ Gly $^{12}$-Lys ${ }^{13}$ that has been proposed to adopt a turn-like conformation (Ishima et al., 1991). The crucial residues Leu ${ }^{11}$ and Gly ${ }^{12}$ (Betts et al., 2003), occupying the positions $i+1$ and $i+2$ of the putative turn, respectively, are flanked sequentially by an acidic and a basic amino acid residue that possibly stabilize the turn-like conformation via salt bridge formation and provide the chemical prerequisite for macrolactamization. In this study, we investigated the influence of macrolactamization at this site on the inhibitory potency of $\mathrm{CP} 1 \mathrm{~B}$ in a systematical manner. To reduce the synthetic effort, a truncated version of CP1B, the 20-mer CP1B-[4-23] (7), was used. We identified CP1B-[4-23] (7) as core sequence necessary to essentially maintain the affinity/selectivity profile of full-length CP1B, taking into account the selectivity aspect that had been neglected in the previously published truncation studies (Betts and Anagli, 2004).

\section{Results}

\section{Selectivity profiles of truncated linear calpastatin peptides}

To assess the selectivity profile of truncated calpastatin peptides within the group of papain-like cysteine proteases, we have selected cathepsin $B$ and $L$ as representative probes. Three groups of truncated calpastatin peptides were synthesized on solid support by the standard Fmoc/tBu scheme. The first and the second group comprise $\mathrm{N}$-terminally and $\mathrm{C}$-terminally truncated variants of CP1B-[1-27] (1), respectively, whereas the third group includes peptides truncated at both termini (Figure 1A). The measured $K_{\mathrm{i}}$ values of these peptides for the inhibition of $\mu$-calpain, cathepsin $B$ and $L$ are summarized in Table 1. N-terminal truncation by three and five ( 3 and 4 , respectively) as well as C-terminal truncation by two and four amino acid residues (5 and $\mathbf{6}$, respectively) does not influence the affinity/selectivity profile significantly compared to 1 . Among the calpastatin peptides truncated at both termini, CP1B-[4-23] (7) is the most potent inhibitor $\left(K_{\mathrm{i}}=26 \mathrm{~nm}\right)$, which blocks the proteolytic activity $\mu$-calpain by a factor of 1000 more efficiently than that of cathepsin L. Moreover, peptide 7 marks a limit for the truncation tolerated at both termini. Beyond this limit, as clearly documented by $\mathbf{8}$ and $\mathbf{9}$, a total loss of affinity and selectivity was observed. To reduce the synthetic effort, we have replaced CP1B-[1-27] (1) by CP1B-[4-23] (7) in all further SAR-investigations.

\section{SAR studies based on linear calpastatin peptides}

To gain information on the individual roles of the two turnlike structural elements, the inhibitory properties of the 
Table 1 Activity/selectivity profiles of linear and conformationally constrained calpastatin peptides.

\begin{tabular}{|c|c|c|c|c|}
\hline \multirow[t]{2}{*}{ Inhibitor } & \multirow{2}{*}{$\frac{\mu \text {-Calpain }}{K_{\mathrm{i}}(\mu \mathrm{M})^{\mathrm{a}}}$} & \multirow{2}{*}{$\frac{\text { Cathepsin L }}{K_{\mathrm{i}}(\mu \mathrm{M})^{\mathrm{a}}}$} & \multirow{2}{*}{$\frac{\text { Cathepsin B }}{K_{\mathrm{i}}(\mu \mathrm{M})^{\mathrm{a}}}$} & \multirow[t]{2}{*}{ Ratio, CL/ $\mu$-calpain } \\
\hline & & & & \\
\hline 1 & $0.0002^{b}$ & $6^{b}$ & $\geq 500^{b}$ & 30000 \\
\hline 2 & $6^{\mathrm{b}}$ & $6^{\mathrm{b}}$ & $\geq 500^{\mathrm{b}}$ & 1 \\
\hline 3 & 0.0006 & 9.5 & $\geq 600$ & 15830 \\
\hline 4 & 0.0022 & 9.7 & $\geq 600$ & 4410 \\
\hline 5 & 0.0005 & 45 & $\geq 600$ & 90000 \\
\hline 6 & 0.0008 & 21 & $\geq 600$ & 26250 \\
\hline 7 & 0.026 & 20 & n.d. & 1000 \\
\hline 8 & 0.093 & 15 & 4.3 & 161 \\
\hline 9 & 17 & 124 & $\geq 900$ & 7.3 \\
\hline 10 & 6.9 & 1.0 & 60 & 0.14 \\
\hline 11 & 35 & 10 & $\geq 200$ & 0.29 \\
\hline 12 & 11.7 & 28 & n.d. & 2.4 \\
\hline 13 & 726 & 44 & 32 & 0.06 \\
\hline 14 & 0.036 & 15 & $\geq 400$ & 420 \\
\hline 15 & 0.039 & 13 & $\geq 400$ & 330 \\
\hline 16 & 0.027 & 18 & $\geq 400$ & 230 \\
\hline 17 & 1.4 & 1.3 & 3.7 & 0.9 \\
\hline
\end{tabular}

aMean of 5-10 experiments with different inhibitor concentrations (SD $<10 \%)$. Values marked by ' $\geq$ ' are 10 -fold the highest used inhibitor concentration that resulted in less than $10 \%$ inhibition.

'Data taken from Gil-Parrado et al. (2003).

n.d., not determined.

peptides 10 and 11, representing the first and second half of CP1B-[1-27] (1), respectively, were analyzed (Table 1). In particular, peptide 10 comprising the turnlike sequence $\mathrm{Glu}^{10}$-Leu ${ }^{11}$-Gly ${ }^{12}$-Lys ${ }^{13}$ is only a poor inhibitor of $\mu$-calpain $\left(K_{\mathrm{i}}=6.9 \mu \mathrm{M}\right)$. Similarly, peptide 11 that includes the residues Pro $^{20}-$ Lys $^{21}-\mathrm{Tyr}^{22}$-Arg ${ }^{23}$ being part of the second turn-like structural element, inhibits $\mu$-calpain with even lower affinity $\left(K_{\mathrm{i}}=35 \mu \mathrm{M}\right)$. Considering the tripeptide sequence $\mathrm{Arg}^{14}$-Glu ${ }^{15}-\mathrm{Val}{ }^{16}$ merely as a linker that connects the two turn-like structural elements, a peptide was designed where this connecting sequence was replaced by a non-peptidic spacer. The flexible PEG amino acid 8-amino-3,6-dioxaoctanoic acid was selected as a spacer, which should provide a spatial substitution for the tripeptide portion. The kinetic analysis of this peptide 12 revealed poor inhibitory properties $\left(K_{\mathrm{i}}=11.7 \mu \mathrm{M}\right)$. Furthermore, we applied the retro-inverso approach on the sequence of our truncated calpastatin peptide CP1B-[4-23] (7). It turned out that the corresponding retro-inverso derivative $\mathbf{1 3}$ is almost completely inactive $\left(K_{\mathrm{i}}=726 \mu \mathrm{M}\right)$.

\section{Sequence alignment of the turn-like region Glu $^{10}$ Leu $^{11}$-Gly ${ }^{12}$-Lys ${ }^{13}$ of CP1B-[4-23] (7)}

In a next step, to obtain a more precise picture of the conformation that the core sequence (7, CP1B-[4-23]) adopts upon binding to $\mu$-calpain, the turn-like region, i.e., Glu10-Leu ${ }^{11}-$ Gly $^{12}$-Lys ${ }^{13}$ was investigated. A systematical amino acid sequence alignment of subdomains $1 \mathrm{~B}, 2 \mathrm{~B}, 3 \mathrm{~B}$ and $4 \mathrm{~B}$ of calpastatin revealed that this region is highly conserved among different species (Figure 2). In particular, the residues $i+1$ (Leu/Cys) and i+2 (Gly) of the turn-like region are flanked by a basic and an acidic residue in a pairwise manner. In the case of subdomain 1B, position $\mathrm{i}$ is occupied by a Glu and position $\mathrm{i}+3$ by a Lys residue, whereas in the case of subdomains $2 \mathrm{~B}, 3 \mathrm{~B}$ and $4 \mathrm{~B}$ the situation is reversed (Lys in position $\mathrm{i}$ and Glu in position $\mathrm{i}+3$ ). Only subdomain $1 \mathrm{~B}$ from rat and mouse, as well as bovine subdomain $3 \mathrm{~B}$, differ from this pattern. Furthermore, the position preceding this turn-like region (i-1) is occupied by an acidic amino acid residue (Asp/ Glu), the position following this turn-like region $(i+4)$ by a basic amino acid residue (Arg/Lys). However, amongst all species included in the alignment, the subdomains $2 \mathrm{~B}$ deviate substantially from this pattern.

\section{Design and synthesis of conformationally constrained versions of CP1B-[4-23] (7)}

The consensus pattern Glu/Lys ${ }^{10}$ (i) - Leu/Cys ${ }^{11}(i+1)-$ Gly $^{12}(i+2)-$ Lys $/ G^{13}{ }^{13}(i+3)$ extracted from the sequence alignment suggests that a loop-like structure could be stabilized by a salt bridge/ $\mathrm{H}$-bond interaction of the pairs of amino acids with oppositely charged side chains in position $\mathrm{i}$ and $\mathrm{i}+3$. To test this hypothesis, the side chains of Glu10 and Lys ${ }^{13}$ within CP1B-[4-23] (7) were covalently linked by macrolactamization. Furthermore, using different combinations of acidic and basic amino acid residues in positions $i$ and $i+3$, the conformational freedom was restricted successively via the side chain functions of these residues in a systematical manner. Thereby, the sequence is forced into a restricted conformation at this position, starting from a loose loop-like structure and ending up in a tight turn. The sequences of the four constrained peptides are shown in Figure 1B. The synthesis of these conformationally constrained variants of CP1B-[4-23] (7) is outlined in Figure 3. The peptides were synthesized on solid support by the standard Fmoc/tBu scheme. The basic residues in position $\mathrm{i}+3$ were incorporated into the peptide chain Aloc-protected and the acidic residues in position i Al-protected. Prior 


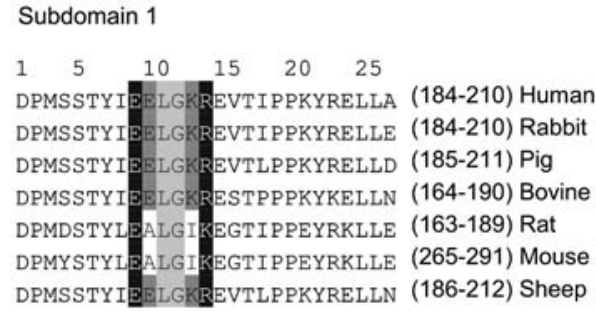

Subdomain 2

\begin{tabular}{|c|c|c|}
\hline & 20 & \\
\hline & DDETI PSEYRLKPA & (318-344) Human \\
\hline AKRKEE & DDETVPAEYRLKPA & (321-347) Rabbit \\
\hline AKAKEEKL & DDETVPPEYRLKPA & (321-347) Pig \\
\hline AKAKEEKV & DEETVPSEYRLKPA & (306-332) Bovine \\
\hline AKAKEERQ & DEDTVPAEYRLKPA & (296-322) Rat \\
\hline AKAKE & DEDTVPAEYRLKPA & (398-424) Mouse \\
\hline AKAKEEKV & DEERVPSEYRLKPA & (321-347) Sheep \\
\hline
\end{tabular}

Subdomain 3

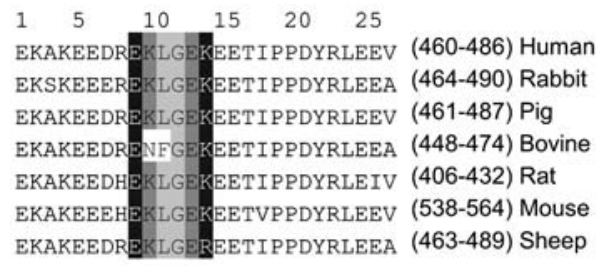

Subdomain 4

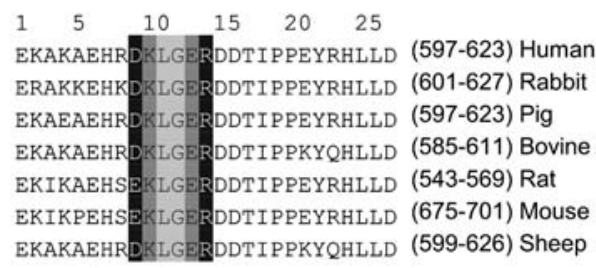

Figure 2 Amino acid sequence alignment of subdomains 1B, $2 \mathrm{~B}, 3 \mathrm{~B}$ and $4 \mathrm{~B}$ of calpastatin from different mammalian species. Positions of shown residues within the complete sequence are given in parentheses. The amino acid residues reflecting the consensus sequence pattern of the turn-like region (residues 10-13 which are supposed to constitute the turn as well as the preceding residue 9 and the following residue 14) are highlighted (residues $\mathrm{i}-1 / \mathrm{i}+4$ : black; residues $\mathrm{i} / \mathrm{i}+3$ : dark-gray; residues $\mathrm{i}+1$ / $\mathrm{i}+2$ : light-gray).

to finishing the complete peptide sequence, the allylbased side chain protection was cleaved by $\operatorname{Pd}(0)$, and the lactam bridge was formed using PyBOP, following a procedure by Teixido et al. (2003).

\section{Inhibition of $\mu$-calpain by conformationally constrained variants of CP1B-[4-23] (7)}

A comparison of the $K_{\mathrm{i}}$ values of the linear core sequence $\mathbf{7}$ with its cyclic counterpart $\mathbf{1 4}$ clearly shows that macrolactamization via the side chains of $\mathrm{Glu}^{10}$ and $\mathrm{Lys}^{13}$ does not affect the inhibitory profile $\left(K_{i}\right.$ of $0.026 \mu \mathrm{M}$ vs. $0.036 \mu \mathrm{M}$, respectively). Furthermore, starting from the amino acid pair Glu(i)/Lys(i+3) (14), over Glu(i)/Orn(i+3) (15), and Glu(i)/Dab(i+3) (16), to Asp(i)/Dab(i+3) (17), the size of the macrolactam ring decreases stepwise by one $\mathrm{CH}_{2}$-group. The $K_{\mathrm{i}}$ values of these peptides are summarized in Table 1. The peptides 14, 15 and 16 are as potent and selective as the linear core sequence 7 . How-

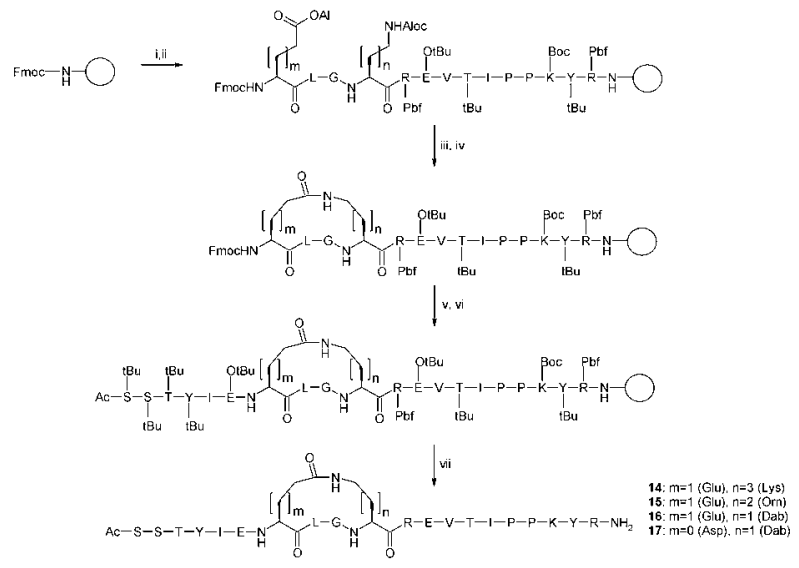

Figure 3 Synthesis of the conformationally constrained calpastatin peptides.

Reaction conditions: (i) a. piperidine/NMP (1:5, v/v), b. FmocXaa-OH/HBTU/HOBt/DIEA (1:1:1:2, 10 equiv.), NMP, 10 cycles of automated single coupling; (ii) a. piperidine/NMP $(1: 5, \mathrm{v} / \mathrm{v})$, b. Fmoc-Xaa-OH/HBTU/HOBt/DIEA (1:1:1:1, 4 equiv.), DMF, 4 cycles of manual double coupling; (iii) $\mathrm{Pd}\left(\mathrm{PPh}_{3}\right)_{4}(0.1$ equiv.), $\mathrm{PhSiH}_{3}$ (5 equiv.), DCM; (iv) PyBOP/HOBt/DIEA (1:1:2, 5 equiv.), DMF; (v) a. piperidine/NMP (1:5, v/v), b. Fmoc-Xaa-OH/HBTU/ HOBt/DIEA (1:1:1:2, 10 equiv.), NMP, 6 cycles of automated double coupling; (vi) a. piperidine/NMP (1:5, v/v), b. $\mathrm{Ac}_{2} \mathrm{O} / 2,6-$ lutidine/DMF (5:6:89, v/v/v); (vii) $\quad \mathrm{TFA} / \mathrm{H}_{2} \mathrm{O} / \mathrm{TIS} \quad$ (95:2.5:2.5, $\mathrm{v} / \mathrm{v} / \mathrm{v})$.

ever, the constraint introduced by the amino acid pair $\mathrm{Asp}(\mathrm{i}) / \mathrm{Dab}(\mathrm{i}+3)$ with the smallest macrolactam ring is accompanied by a substantial loss in affinity in comparison to 7 ( $K_{\mathrm{i}}$ of $1.4 \mu \mathrm{M}$ vs. $0.026 \mu \mathrm{M}$, respectively).

\section{D visualization of the conformationally constrained region}

A 3D model of the conformationally constrained part of 16 induced by the macrolactam ring was built (Figure 4). Besides the modified consensus sequence portion (i)-(i+3), (Glu ${ }^{10}-$ Leu $^{11}-$ Gly $^{12}-$ Dab $\left.^{13}\right)$, the observation was taken into account that within the subdomains 1, 3 and 4 the positions ( $i-1)$ preceding and $(i+4)$ following this

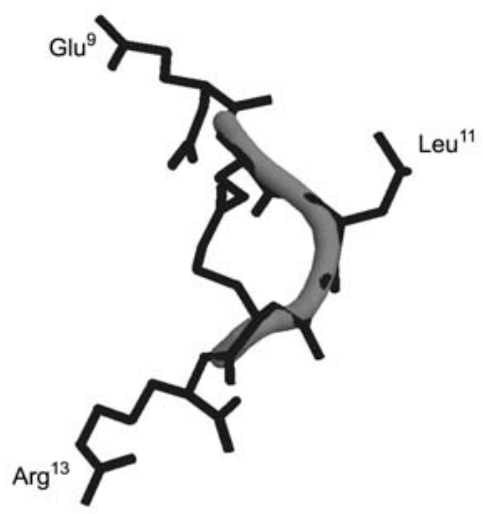

Figure $43 \mathrm{D}$ visualization of the conformationally constrained region (i.e., Glu' - Glu $^{10}-$ Leu $^{11}-$ Gly $^{12}-$ Dab $^{13}-$ Arg $^{14}$ ) of peptide 16. In the model, the $\mathrm{N}$-terminus of this peptide portion is acetylated and the C-terminus amidated. The peptide is shown in stick representation, the amino acid residues $\mathrm{Glu}^{10}$, $\mathrm{Leu}^{11}$ and $\mathrm{Arg}^{13}$ are labeled, and the loop-like conformation of the peptide backbone is indicated by a gray ribbon. 
region are occupied in a systematical manner by an acidic and a basic amino acid residue, respectively (see above). Therefore, the residues $\mathrm{i}-1\left(\mathrm{Glu}^{9}\right)$ and $\mathrm{i}+4\left(\mathrm{Arg}^{14}\right)$ were also included in the model. Inspection of the model revealed a spatial array of a positively charged, a hydrophobic, and a negatively charged residue presented by the loop region.

\section{Discussion}

To reduce the synthetic effort for SAR investigations with the full-length calpastatin peptide, CP1B-[1-27] (1), we were interested in a core sequence that reliably reproduces the affinity/selectivity profile of $\mathbf{1}$. Extending earlier rough determinations of the affinity of truncated calpastatin peptides (Uemori et al., 1990), the group of Anagli has investigated the influence of truncation on the affinity of 1 (Betts and Anagli, 2004). Including the aspect of selectivity, we have reexamined these experiments, using, besides cathepsin $B$, in particular cathepsin $L$ as a reliable marker to estimate the selectivity of inhibition within the family of papain-like cysteine proteases. Generally, our data are consistent with the affinities previously reported (Betts and Anagli, 2004). N-terminal truncation of the full-length sequence by three amino acids (3, $K_{\mathrm{i}}=0.0006 \mu \mathrm{M}$; ratio $\mathrm{CL} / \mu$-calpain 15830 ) as well as C-terminal truncation by four residues $\left(6, K_{i}=0.0008 \mu \mathrm{M}\right.$; ratio $\mathrm{CL} / \mu$-calpain 26250$)$ does not influence the inhibition profile compared to $1\left(K_{\mathrm{i}}=0.0002 \mu \mathrm{M}\right.$; ratio $\mathrm{CL} / \mu$ calpain 30000$)$. A combination of both truncations yielded a calpastatin peptide of 20 amino acids length, i.e., CP1B-[4-23] (7), which still displayed a reasonable inhibitory profile $\left(K_{\mathrm{i}}=0.026 \mu \mathrm{M}\right.$; ratio $\mathrm{CL} / \mu$-calpain 1000$)$. However, beyond this level of truncation (compounds 8 and 9) a drastic loss of affinity and selectivity was observed. Thus, 7 represent a core sequence comprising the minimum requirements to selectively block the proteolytic activity of $\mu$-calpain among other papain-like cysteine proteases.

NMR investigations of $\mathbf{1}$ in DMSO (Ishima et al., 1991) suggest that the sequence portions Glu ${ }^{10}-$ Leu $^{11}-$ Gly $^{12}$ Lys $^{13}$ and Pro ${ }^{20}-$ Lys $^{21}-$ Tyr $^{22}$-Arg ${ }^{23}$ adopt turn-like conformations. Furthermore, by a systematical $\beta$-Ala scan the residues $\mathrm{Leu}^{11}$ and $\mathrm{Gly}^{12}$, as well as the residues $\mathrm{Thr}^{17}$, $\mathrm{Il}^{18}$, and $\mathrm{Pro}^{19}$, have been identified to be crucial for the affinity of 1 (Betts et al., 2003). Together, these observations point towards two hot spots (Betts and Anagli, 2004) responsible for binding of 1 to calpain. Surprisingly, peptides 10 and 11 comprising the individual first and second hot spot region, respectively, exhibit only poor inhibitory activities. Even an equimolar mixture of those peptides did not reconstitute the inhibitory activity of 1 (Betts and Anagli, 2004). Based on these data, Anagli's group introduced the 'gate model' for the inhibition of calpain: the peptide sequence between the two hot spots, i.e., Lys ${ }^{13}-\mathrm{Arg}^{14}-\mathrm{Glu}^{15}-\mathrm{Val}^{16}$, positioned appropriately by the interactions of the two hot spots with calpain, act as a gate blocking the access of substrates to the active site (Betts and Anagli, 2004). To gain more information on the role of this gate, we have designed peptide 12 , based on the core sequence 7 , where the amino acid residues $\mathrm{Arg}^{14}-\mathrm{Glu}^{15}-\mathrm{Va}{ }^{16}$ are replaced by the flexible PEG amino acid 8-amino-3,6-dioxaoctanoic acid that should provide a correct spatial arrangement of the two hot spot regions. However, the low affinity of $\mathbf{1 2}$ $\left(K_{\mathrm{i}}=11.7 \mu \mathrm{M}\right)$ supports the notion that not only the correct spacing of the crucial binding elements is required to restore the affinity of $\mathbf{1}$, but also the correct conformation provided by the tripeptide sequence. Furthermore, the retro-inverso peptide of the core sequence (i.e., 13, $\left.K_{\mathrm{i}}=726 \mu \mathrm{M}\right)$ demonstrates that besides the correct spatial positioning of the amino acid side chains, the peptide back bone also has a strong influence on the affinity.

The fact that the crucial amino acid residues Leu ${ }^{11}$ and Gly $^{12}$ (Betts et al., 2003) occupy the positions $i+1$ and $i+2$ of the proposed $\beta$-turn (Ishima et al., 1991), respectively, prompted us to analyze the amino acid sequence of this region systematically. The sequence alignment of peptides derived from subdomains $1 \mathrm{~B}, 3 \mathrm{~B}$ and $4 \mathrm{~B}$ of different species revealed a consensus sequence for this turn region, i.e., Glu/Asp ${ }^{9}(\mathrm{i}-1)-\mathrm{Glu} / \mathrm{Lys}^{10}$ (i) - Leu $^{11}(\mathrm{i}+1)$ - Gly ${ }^{12}(i+2)-$ Lys $_{\text {Glu }}{ }^{13}(i+3)-$ Arg/Lys $^{14}(i+4)$. However, peptides derived from subdomains $2 \mathrm{~B}$ show a substantially different sequence pattern. Correspondingly, a comparison of the inhibitory potency of the subdomains $1 \mathrm{~B}$, $2 \mathrm{~B}, 3 \mathrm{~B}$ and $4 \mathrm{~B}$ from rabbit calpastatin has revealed that $2 B$ is by far the least potent inhibitor of $\mu$-calpain (Kawasaki et al., 1989). Very recently, these findings have been confirmed by surface plasmon resonance measurements (Hanna et al., 2007). It is striking to observe that in the case of $1 \mathrm{~B}$ peptides the residues $\mathrm{Leu}^{11}$ and Gly ${ }^{12}$ are flanked by Glu in position $i$ and Lys in position $i+3$, whereas in the case of 3B and $4 \mathrm{~B}$ peptides the basic Lys (position i) is followed by an acidic Glu (position $i+3$ ). This points towards a turn conformation at this site that is possibly stabilized by a salt bridge interaction of the oppositely charged side chain functionalities. Furthermore, one would expect that this type of local conformation would orientate the oppositely charged residues in position $\mathrm{i}-1$ and $\mathrm{i}+4$ in a defined spatial manner. To test this hypothesis, $\mathbf{1 4}$ was synthesized where the putative salt bridge stabilized turn-like conformation in the parent linear core sequence 7 was covalently fixed by macrolactamization. A comparison of the $K_{\mathrm{i}}$ values clearly shows that 14 is virtually as potent as $7\left(K_{\mathrm{i}}\right.$ of $0.036 \mu \mathrm{M}$ vs. $0.026 \mu \mathrm{M}$ ). This finding is supportive for a turn-like conformation stabilized by a salt bridge formed between side chain carboxyl function of $\mathrm{Glu}^{10}$ and the side chain amino function of Lys ${ }^{13}$.

To gain more information about the geometry of this turn-like structure, the local conformational degrees of freedom were successively reduced by stepwise removal of $\mathrm{CH}_{2}$-groups within the macrolactam ring. The constraint induced by removal of one $\mathrm{CH}_{2}$-group (15) as well as two $\mathrm{CH}_{2}$-groups (16) does not influence the inhibitory profile substantially compared to $7\left(K_{\mathrm{i}}\right.$ of $0.039 \mu \mathrm{M}$ and $0.027 \mu \mathrm{M}$ vs. $0.026 \mu \mathrm{M}$, respectively). However, removal of three $\mathrm{CH}_{2}$-groups (17), corresponding conformationally to a tight $\beta$-turn is accompanied with a severe loss of inhibitory potency $\left(K_{\mathrm{i}}=1.4 \mu \mathrm{M}\right)$. These data clearly support the notion that the peptide portion Glu ${ }^{10}$ Leu $^{11}$-Gly ${ }^{12}$ Lys $^{13}$ adopts a more loop-like structure rather than a 
$\beta$-turn as earlier proposed (Ishima et al., 1991), pointing to a chain reversal of the $1 \mathrm{~B}$ peptide at this site in the peptide sequence. Moreover, it seems that in contrast to the constrained variants 14,15 and 16 , in peptide 17 the amino acid portion CP1B-[4-9] preceding the turn region as well as the amino acid portion CP1B-[14-23] following the turn region cannot adopt the proper orientation and/or conformation upon binding to $\mu$-calpain.

Based on X-ray data of the interaction of a subdomain 1C peptide with domain $\mathrm{VI}$ of calpain and the homology model of the interaction of a subdomain 1A peptide with domain IV of calpain, models for the interaction of an entire inhibitory domain of calpastatin with calpain have been proposed (Todd et al., 2003; Wendt et al., 2004). To properly connect the subdomains $1 \mathrm{~A}$ and $1 \mathrm{C}$, both models claim a reversal of the peptide chain within the region corresponding to subdomain 1B. Our data derived from the conformationally constrained variants of 7 presumably indicate that the chain reversal is centered at the tetrapeptide portion Glu10-Leu ${ }^{11}$-Gly ${ }^{12}$-Lys ${ }^{13}$.

The consensus sequence of the loop site revealed that the polarity pattern of the residues $\mathrm{i}-1$ (Glu or Asp: acidic) preceding and $i+4$ (Lys, Arg: basic) following this loop is highly conserved (Figure 2). The consequence of the loop-like structure is that these particular residues occupy spatially defined positions. In combination with the hydrophobic side chain of Leu ${ }^{11}$, which has been shown to be highly sensitive to modifications (Betts and Anagli, 2004), these residues could be responsible for the correct positioning of the $1 \mathrm{~B}$ peptide on the calpain surface by addressing complementary binding pockets, and thereby blocking the access of substrates to the active site.

In conclusion, based on conformationally restricted variants of subdomain $1 \mathrm{~B}$ of human calpastatin, a first model of the biologically active conformation has been provided. In particular, macrolactamization studies revealed that the tetrapeptide portion Glu ${ }^{10}$ Leu $^{11}$-Gly ${ }^{12}$ Lys ${ }^{13}$ adopts a loop-like conformation inducing a reversal of the peptide chain at this site upon binding to $\mu$-calpain.

\section{Materials and methods}

\section{Materials}

Solvents and reagents were of the highest purity commercially available and were used without further purification. Amino acid derivatives were purchased from Iris Biotech $\mathrm{GmbH}$ (Marktredwitz, Germany) and Fluka (Buchs, Switzerland), the Rink-Amide resin from NovaBiochem/Merck Biosciences AG (Läufelfingen, Germany), Fmoc-8-amino-3,6-dioxaoctanoic acid from NeoMPS SA (Strasbourg, France), CP1B-[1-27] (1) as well as its scrambled derivative 2 from Calbiochem (Bad Soden, Germany). Automated peptide synthesis was carried out on a batch synthesizer 433A (Applied Biosystems, Foster City, CA, USA) equipped with a UV/vis detector PE series 200 from Perkin Elmer (Überlingen, Germany) for monitoring of the Fmoc-cleavage. Manual peptide synthesis as well as all other manually performed synthetic steps were carried out on an IKA KS 130 basic laboratory shaker (IKA Werke $\mathrm{GmbH}$, Staufen, Germany) using plastic syringes type Discardit II from Becton Dickinson (Franklin Lakes, NJ, USA) equipped with $\mathrm{PE}$ frits (35 $\mu \mathrm{m}$ pores size) and PE stoppers from Roland Vetter Laborbedarf (Ammerbuch, Germany). LC-MS mass spectra were recorded with a PE Sciex API 165 ESI-MS spectrometer and a microgradient system $140 \mathrm{C}$ (Applied Biosystems, Framingham, MA, USA). Nucleosil 100-5 $\mathrm{C}_{8} \mathrm{RP}$ columns (Macherey-Nagel, Düren, Germany) were used with a linear gradient of $0.1 \%$ TFA in $\mathrm{H}_{2} \mathrm{O}$ and $0.08 \%$ TFA in $\mathrm{CH}_{3} \mathrm{CN}$ from 95:5 to 5:95. The MS spectra were processed with $\mathrm{PE}$ Sciex BioMultiView software (V. 1.3.1, Applied Biosystems). Analytical RP-HPLC was performed with Waters equipments using Chromolith Performance RP-18e $(100 \times 4.6$ mm; VWR International $\mathrm{GmbH}$, Darmstadt, Germany) columns and eluting with linear gradients from $5 \% \mathrm{CH}_{3} \mathrm{CN}$ in $\mathrm{H}_{2} \mathrm{O} / 95 \% \mathrm{H}_{3} \mathrm{PO}_{4}\left(2 \%\right.$ in $\left.\mathrm{H}_{2} \mathrm{O}\right)$ to $90 \% \mathrm{CH}_{3} \mathrm{CN}$ in $\mathrm{H}_{2} \mathrm{O} / 10 \% \mathrm{H}_{3} \mathrm{PO}_{4}\left(2 \%\right.$ in $\left.\mathrm{H}_{2} \mathrm{O}\right)$ within 6 min at a flow rate of $3 \mathrm{ml} / \mathrm{min}$. For preparative reversed-phase HPLC, Gilson-Abimed equipments (Middleton, WI, USA) and Nucleosil 100-5 C18 columns (Macherey-Nagel) were used and compounds were eluted with linear gradients of $0.1 \%$ TFA in $\mathrm{H}_{2} \mathrm{O}$ and $0.08 \%$ TFA in $\mathrm{CH}_{3} \mathrm{CN}$. The 3D model of the conformationally constrained region of $\mathbf{1 6}$ was built using the program HyperChem $^{\text {TM }}$ (Release 3, Hypercube, Inc., Gainesville, FL, USA).

\section{Synthesis of linear calpastatin peptides}

The linear peptides were synthesized using an automated peptide synthesizer according to the Fmoc/tBu strategy. Fmocprotected amino acid with the following side-chain protecting groups were used: OtBu (Asp and Glu), tBu (Ser, Thr and Tyr), Boc (Lys) and Pbf (Arg). In the case of the retro-inverso peptide 13 , the corresponding D-amino acids were used. The coupling was performed with Fmoc-Xaa-OH/HBTU/HOBt/DIEA (1:1:1:2, 10 equiv.) in NMP using the standard FastMoc ${ }^{T M}$ protocol (Applied Biosystems) for single and double coupling, respectively. Unless otherwise stated, single coupling was performed. The loading of the Rink-Amid resin $(0.1 \mathrm{mmol})$ with the first amino acid was also performed using the synthesizer under the same conditions as for a single coupling step. After each coupling step, the Fmoc group was cleaved using piperidine/NMP $(1: 5, v / v)$. The acetylation of the $\mathrm{N}$-terminal amino group was performed manually using $\mathrm{Ac}_{2} \mathrm{O} / 2,6$-lutidine/DMF $(5: 6: 89, \mathrm{v} / \mathrm{v} / \mathrm{v})$. The final deprotection was also carried out manually using TFA/ $\mathrm{H}_{2} \mathrm{O} / \mathrm{TIS}(95: 2.5: 2.5, \mathrm{v} / \mathrm{v} / \mathrm{v})$. The crude peptides were precipitated by adding the cleavage solution dropwise into ice-cold tert-butyl methyl ether/hexane $(2: 1, v / v)$. The precipitate was collected by centrifugation and purified by preparative RP-HPLC. Homogenous fractions were pooled and lyophilized.

AC-SSTYIEELGKREVTIPPKYRELLA- $\mathrm{NH}_{2}$ (3) Double coupling starting with the 4th Glu; colorless lyophilisate: yield: 164 mg (58\%); HPLC $\left(t_{\mathrm{R}}=2.1 \mathrm{~min}\right)$; ESI-MS: $m / z=1418.0[\mathrm{M}+2 \mathrm{H}]^{2+}$, $945.8[\mathrm{M}+3 \mathrm{H}]^{3+}, 709.4[\mathrm{M}+4 \mathrm{H}]^{4+} ; M_{\mathrm{r}}=2834.29$ calculated for $\mathrm{C}_{128} \mathrm{H}_{209} \mathrm{~N}_{33} \mathrm{O}_{39}$.

Ac-TYIEELGKREVTIPPKYRELLA-NH ${ }_{2}$ (4) Double coupling starting with the 4th Glu; colorless lyophilisate: yield: $183 \mathrm{mg}$ (69\%); HPLC $\left(t_{\mathrm{R}}=2.1 \mathrm{~min}\right)$; ESI-MS: $m / z=1330.8[\mathrm{M}+2 \mathrm{H}]^{2+}$, $887.4[\mathrm{M}+3 \mathrm{H}]^{3+}, 666.0[\mathrm{M}+4 \mathrm{H}]^{4+} ; M_{\mathrm{r}}=2660.13$ calculated for $\mathrm{C}_{122} \mathrm{H}_{199} \mathrm{~N}_{31} \mathrm{O}_{35}$

Ac-DPMSSTYIEELGKREVTIPPKYREL- $\mathrm{NH}_{2}$ (5) Double coupling starting with the 4th Glu; colorless lyophilisate: yield: 197 mg (66\%); HPLC $\left(t_{\mathrm{R}}=2.0 \mathrm{~min}\right)$; ESI-MS: $m / z=1498.0[\mathrm{M}+2 \mathrm{H}]^{2+}$, $998.4[\mathrm{M}+3 \mathrm{H}]^{3+}, 748.8[\mathrm{M}+4 \mathrm{H}]^{4+} ; M_{\mathrm{r}}=2993.39$ calculated for $\mathrm{C}_{133} \mathrm{H}_{214} \mathrm{~N}_{34} \mathrm{O}_{42} \mathrm{~S}$.

Ac-DPMSSTYIEELGKREVTIPPKYR- $\mathrm{NH}_{2}$ (6) Double coupling starting with the 3rd Glu; colorless lyophilisate: yield: 195 mg (71\%); HPLC $\left(t_{\mathrm{R}}=1.9 \mathrm{~min}\right)$; ESI-MS: $m / z=1376.4[\mathrm{M}+2 \mathrm{H}]^{2+}$, 
$918.0[\mathrm{M}+3 \mathrm{H}]^{3+}, 688.6[\mathrm{M}+4 \mathrm{H}]^{4+} ; M_{\mathrm{r}}=2751.18$ calculated for $\mathrm{C}_{122} \mathrm{H}_{196} \mathrm{~N}_{32} \mathrm{O}_{38} \mathrm{~S}$.

Ac-SSTYIEELGKREVTIPPKYR- $\mathrm{NH}_{2}$ (7) Double coupling starting with the 3rd Glu; colorless lyophilisate: yield: $180 \mathrm{mg}$ $(75 \%) ; \mathrm{HPLC}\left(t_{\mathrm{R}}=1.8 \mathrm{~min}\right)$; ESI-MS: $m / z=1204.8[\mathrm{M}+2 \mathrm{H}]^{2+}$, $803.4[\mathrm{M}+3 \mathrm{H}]^{3+}, 603.0[\mathrm{M}+4 \mathrm{H}]^{4+} ; M_{\mathrm{r}}=2407.77$ calculated for $\mathrm{C}_{108} \mathrm{H}_{175} \mathrm{~N}_{29} \mathrm{O}_{33}$.

Ac-TYIEELGKREVTIPPKYR- $\mathrm{NH}_{2}$ (8) Double coupling starting with the 3rd Glu; colorless lyophilisate: yield: $148 \mathrm{mg}(66 \%)$; HPLC $\left(t_{\mathrm{R}}=1.8 \mathrm{~min}\right)$; ESI-MS: $\mathrm{m} / \mathrm{z}=1117.6[\mathrm{M}+2 \mathrm{H}]^{2+}, 745.4$ $[\mathrm{M}+3 \mathrm{H}]^{3+}, \quad 559.4 \quad[\mathrm{M}+4 \mathrm{H}]^{4+} ; \quad M_{\mathrm{r}}=2233.62$ calculated for $\mathrm{C}_{102} \mathrm{H}_{165} \mathrm{~N}_{27} \mathrm{O}_{29}$.

Ac-SSTYIEELGKREVTIPPK- $\mathrm{NH}_{2}$ (9) Double coupling starting with the 3rd Glu; colorless lyophilisate: yield: $153 \mathrm{mg}(73 \%)$; HPLC $\left(t_{\mathrm{R}}=1.8 \mathrm{~min}\right)$; ESI-MS: $m / z=1044.8[\mathrm{M}+2 \mathrm{H}]^{2+}, 697.0$ $[\mathrm{M}+3 \mathrm{H}]^{3+} ; M_{\mathrm{r}}=2088.41$ calculated for $\mathrm{C}_{93} \mathrm{H}_{154} \mathrm{~N}_{24} \mathrm{O}_{30}$.

Ac-DPMSSTYIEELGK-NH $\mathbf{N H}_{2}$ (10) Colorless lyophilisate: yield: $109 \mathrm{mg}$ (72\%); HPLC ( $\left.t_{\mathrm{R}}=2.0 \mathrm{~min}\right)$; ESI-MS: $\mathrm{m} / \mathrm{z}=1511.8$ $[\mathrm{M}+\mathrm{H}]^{+}, \quad 756.2 \quad[\mathrm{M}+2 \mathrm{H}]^{2+} ; \quad M_{\mathrm{r}}=1510.7 \quad$ calculated for $\mathrm{C}_{65} \mathrm{H}_{103} \mathrm{~N}_{15} \mathrm{O}_{24} \mathrm{~S}$.

Ac-REVTIPPKYRELLA-NH $\mathrm{N}_{2}$ (11) Colorless lyophilisate: yield: $134 \mathrm{mg}(78 \%)$; HPLC ( $\left.t_{\mathrm{R}}=1.8 \mathrm{~min}\right)$; ESI-MS: $\mathrm{m} / \mathrm{z}=1727.4$ $[\mathrm{M}+\mathrm{H}]^{+}, 864.0[\mathrm{M}+2 \mathrm{H}]^{2+}, 576.2[\mathrm{M}+3 \mathrm{H}]^{3+} ; M_{\mathrm{r}}=1726.1 \mathrm{calcu}-$ lated for $\mathrm{C}_{79} \mathrm{H}_{132} \mathrm{~N}_{22} \mathrm{O}_{21}$.

AC-SSTYIEELGK-NH- $\left(\mathrm{CH}_{2} \mathrm{O}\right)_{2}-\mathrm{CH}_{2} \mathrm{C}(\mathrm{O})-\mathrm{TIPPKYR}-\mathrm{NH}_{2}$ Double coupling starting with the 2 nd Glu; colorless lyophilisate: yield: $95 \mathrm{mg}(44 \%)$; HPLC ( $\left.t_{\mathrm{R}}=1.8 \mathrm{~min}\right)$; ESI-MS: $\mathrm{m} / \mathrm{z}=1084.8$ $[\mathrm{M}+2 \mathrm{H}]^{2+}, 723.8[\mathrm{M}+3 \mathrm{H}]^{3+} ; \quad M_{\mathrm{r}}=2168.45$ calculated for $\mathrm{C}_{98} \mathrm{H}_{158} \mathrm{~N}_{24} \mathrm{O}_{31}$.

Ac-rykppitverkgleeiytss- $\mathrm{NH}_{2}$ (13) Double coupling starting with Val; colorless lyophilisate: yield: $98 \mathrm{mg}(41 \%)$; $\mathrm{HPLC}\left(t_{\mathrm{R}}=2.3\right.$ $\mathrm{min})$; ESI-MS: $m / z=1205.0[\mathrm{M}+2 \mathrm{H}]^{2+}, 803.6[\mathrm{M}+3 \mathrm{H}]^{3+}, 603.0$ $[\mathrm{M}+4 \mathrm{H}]^{4+} ; M_{\mathrm{r}}=2407.8$ calculated for $\mathrm{C}_{108} \mathrm{H}_{175} \mathrm{~N}_{29} \mathrm{O}_{33}$.

\section{Synthesis of conformationally constrained calpastatin peptides}

The peptide sequence REVTIPPKYR was synthesized using a Rink-Amide resin $(0.1 \mathrm{mmol})$, as described for the linear peptides. The following four amino acids corresponding to the sequence $X_{2}$ LGX $_{1}$ (14: $X_{1}=$ Lys, $X_{2}=$ Glu; 15: $X_{1}=$ Orn, $X_{2}=$ Glu; 16: $X_{1}=$ Dab, $X_{2}=$ Glu; 17: $X_{1}=$ Dab, $X_{2}=$ Asp) were added manually by double coupling (60 min for each coupling step) with Fmoc-XaaOH/HBTU/HOBt/DIEA (1:1:1:1, 4 equiv.) in DMF (3 ml). The side chains of Asp and Glu were OAl, those of Lys, Orn and Dab Aloc-protected. After each coupling step, the resin was washed with DMF, DCM and $i \mathrm{PrOH}$ sequentially $(3 \times 3 \mathrm{ml}$ each). To cleave the allyl-based protecting groups, the N-terminally Fmoc-protected resin-bound peptide was treated $(3 \times 15 \mathrm{~min})$ with $\mathrm{Pd}\left(\mathrm{PPh}_{3}\right)_{4}$ (0.1 equiv.) and $\mathrm{PhSiH}_{3}(5$ equiv.) in dry $\mathrm{DCM}(3 \mathrm{ml})$ under an argon atmosphere. Upon each treatment, the resin was washed with dry DCM $(2 \times 3 \mathrm{ml})$. Finally, the resin was washed with DMF, DCM and $i \mathrm{PrOH}$ sequentially $(3 \times 3 \mathrm{ml}$ each). The macrolactamization $(2 \times 120$ min coupling time) was carried out with PyBOP/HOBt/DIEA (1:1:2, 5 equiv.). In the particular case of $17\left(X_{1}=\right.$ Dab, $\left.X_{2}=G l u\right)$, it was necessary to repeat the macrolactamization step a third time overnight to complete the reaction. The remaining sequence was built up using the synthesizer (double coupling, 10 equiv.). N-terminal acetylation, final deprotection and purification was performed as described for the linear peptides.
14 Colorless lyophilisate: yield: $115 \mathrm{mg}(48 \%)$; HPLC $\left(t_{\mathrm{R}}=2.0\right.$ $\mathrm{min}) ; \quad$ ESI-MS: $m / z=1195.6[\mathrm{M}+2 \mathrm{H}]^{2+} ; 797.6[\mathrm{M}+3 \mathrm{H}]^{3+}$; $M_{\mathrm{r}}=2389.75$ calculated for $\mathrm{C}_{108} \mathrm{H}_{173} \mathrm{~N}_{29} \mathrm{O}_{32}$.

15 Colorless lyophilisate: yield: $99 \mathrm{mg}(42 \%)$; HPLC $\left(t_{\mathrm{R}}=2.6\right.$ min); ESI-MS: $m / z=1188.4 \quad[\mathrm{M}+2 \mathrm{H}]^{2+} ; 792.8[\mathrm{M}+3 \mathrm{H}]^{3+}$; $M_{\mathrm{r}}=2375.74$ calculated for $\mathrm{C}_{107} \mathrm{H}_{171} \mathrm{~N}_{29} \mathrm{O}_{32}$.

16 Colorless lyophilisate: yield: $116 \mathrm{mg}(49 \%) ; \mathrm{HPLC}\left(t_{\mathrm{R}}=2.3\right.$ min); ESI-MS: $m / z=1181.8 \quad[\mathrm{M}+2 \mathrm{H}]^{2+} ; 788.4 \quad[\mathrm{M}+3 \mathrm{H}]^{3+}$; $M_{\mathrm{r}}=2361.73$ calculated for $\mathrm{C}_{106} \mathrm{H}_{169} \mathrm{~N}_{29} \mathrm{O}_{32}$.

17 Colorless lyophilisate: yield: $65 \mathrm{mg}(28 \%)$; HPLC $\left(t_{\mathrm{R}}=1.7\right.$ $\mathrm{min})$; ESI-MS: $m / z=1175.2[\mathrm{M}+2 \mathrm{H}]^{2+} ; 784.0[\mathrm{M}+3 \mathrm{H}]^{3+}$; $M_{\mathrm{r}}=2347.67$ calculated for $\mathrm{C}_{105} \mathrm{H}_{167} \mathrm{~N}_{29} \mathrm{O}_{32}$.

\section{Inhibition assays and $K_{\mathrm{i}}$ determination}

Enzymes and substrates were obtained as outlined in GilParrado et al. (2003). Inhibition of $\mu$-calpain (0.5-1 nM) was measured at $12^{\circ} \mathrm{C}$ (to slow down inactivation by autolysis) with the fluorogenic substrate Suc-LY-amc $(400 \mu \mathrm{M})$ in $50 \mathrm{~mm}$ Tris/ $\mathrm{HCl}, \mathrm{pH} 7.5,100 \mathrm{~mm} \mathrm{NaCl}, 0.015 \%$ Brij-35, (calpain buffer) and 150-200 $\mu \mathrm{M} \mathrm{CaCl}_{2}, 1 \mathrm{~mm}$ dithiothreitol (DTT). Cathepsin L (5 pM) was assayed at $25^{\circ} \mathrm{C}$ with Z-FR-amc $(4 \mu \mathrm{M})$ and cathepsin B (25 pM) at $30^{\circ} \mathrm{C}$ with Z-FR-amc $(10 \mu \mathrm{M})$ in $0.25 \mathrm{M}$ sodium actetate, pH 5.5, 2 mM EDTA, 0.015\% Brij-35, 1 mm dithiothreitol, freshly added. Continuous assays were performed recording fluorescence (excitation $380 \mathrm{~nm}$, emission $460 \mathrm{~nm}$ ) essentially as described in Machleidt et al. (1993). The enzymes were preactivated with DTT in the presence of substrate and $\mathrm{CaCl}_{2}$ (only with $\mu$-calpain). Then approximately $5-10$ different inhibitor concentrations were added in maximal $1 \%$ of the total test volume of $500 \mu \mathrm{l}$ (dissolved and prediluted in calpain buffer) and the reaction was followed until equilibrium was reached. $K_{\mathrm{i}}$ values for the inhibition of $\mu$-calpain were obtained from presteady state kinetics, fitting the progress data by non-linear regression analysis to the integrated equation of Morrison (1982). From the rate constants $k_{\text {on }}$ and $k_{\text {off }}$, the $K_{\mathrm{i}}$ values were calculated as $K_{\mathrm{i}}=k_{\text {off }} / k_{\text {on }}$. For cathepsin $\mathrm{L}$ and $\mathrm{B}$, the inhibition constants were calculated from the initial and steady state rates using the equation of classical inhibition. $K_{\mathrm{i}}$ values were corrected for competition with the substrates. In cases of less than $10 \%$ inhibition, the $K_{\mathrm{i}}$ value was assumed to be at least 10 -fold the highest used inhibitor concentration.

\section{Acknowledgments}

The study was supported by the DFG with a grant (SCHA 1012/1-2).

\section{References}

Bánóczi, Z., Tantos, A., Farkas, A., Tompa, P., Friedrich, P., and Hudecz, F. (2007). Synthesis of cell-penetrating conjugates of calpain activator peptides. Bioconj. Chem. 18, 130-137.

Barrett, A.J., Rawlings, N.D., and Woessner, J.F. (1998). Handbook of Proteolytic Enzymes (London, UK: Academic Press).

Betts, R. and Anagli, J. (2004). The $\beta$ - and $\gamma-\mathrm{CH}_{2}$ of the B27WT's Leu ${ }^{11}$ and $\mathrm{Ile}^{18}$ side chains play a direct role in calpain inhibition. Biochemistry 43, 2596-2604.

Betts, R., Weinsheimer, S., Blouse, G.E., and Anagli, J. (2003). Structural determinants of the calpain inhibitory activity of calpastatin peptide B27-WT. J. Biol. Chem. 278, 7800-7809.

Donkor, I.O. (2000). A survey of calpain inhibitors. Curr. Med. Chem. 7, 1171-1188.

Gil-Parrado, S., Assfalg-Machleidt, I., Fiorino, F., Deluca, D., Pfeiler, D., Schaschke, N., Moroder, L., and Machleidt, W. (2003). Calpastatin exon 1B-derived peptide, a selective 
inhibitor of calpain: enhancing cell permeability by conjugation with penetratin. Biol. Chem. 384, 395-402.

Goll, D.E., Thompson, V.F., Li, H., Wei, W., and Cong, J. (2003). The calpain system. Physiol. Rev. 83, 731-801.

Hanna, A.H., Garcia-Diaz, B.E., and Davies, P.L. (2007). Calpastatin simultaneously binds four calpains with different kinetic constants. FEBS Lett. 581, 2894-2898.

Hosfield, C.M., Elce, J.S., Davies P.L., and Jia Z. (1999). Crystal structure of calpain reveals the structural basis for $\mathrm{Ca}^{2+}$ dependent protease activity and a novel mode of enzyme activation. EMBO J. 18, 6880-6889.

Ishima, R., Tamura, A., Akasaka, K., Hamaguchi, K., Makino, K., Murachi, T., Hatanaka, M., and Maki, M. (1991). Structure of the active 27-residue fragment of human calpastatin. FEBS Lett. 294, 64-66.

Kawasaki, H., Emori, Y., Imajoh-Ohmi, S., Minami, Y., and Suzuki K. (1989). Identification and characterization of inhibitory sequences in four repeating domains of the endogenous inhibitor for calcium-dependent protease. J. Biochem. (Tokyo) 106, 274-281.

Konno, T., Tanaka, N., Kataoka, M., Takano, E., and Maki, M. (1997). A circular dichroism study of preferential hydration and alcohol effects on a denatured protein, pig calpastatin domain I. Biochim. Biophys. Acta 1342, 73-82.

Machleidt, W., Assfalg-Machleidt, I., and Auerswald, E.A. (1993). Kinetics and molecular mechanism of inhibition of cysteine proteinases by their protein inhibitors. In: Innovations in Proteases and their Inhibitors, F.X. Aviles, ed. (Berlin, Germany: Walter de Gruyter), pp. 179-196.

Maki, M., Bagci, H., Hamaguchi, K., Ueda, M., Murachi, T., and Hatanaka, M. (1989). Inhibition of calpain by a synthetic oligopeptide corresponding to an exon of the human calpastatin gene. J. Biol. Chem. 264, 18866-18869.

Morrison, J.F. (1982). The slow-binding and slow, tight-binding inhibition of enzyme-catalyzed reactions. Trends Biochem. Sci. 7, 102-105.

Mucsi, Z., Hudecz, F., Hollósi, M., Tompa, P., and Friedrich, P. (2003). Binding-induced folding transitions in calpastatin subdomains A and C. Protein Sci. 12, 2327-2336.

Sorimachi, H. and Suzuki, K. (2001). The structure of calpain. J. Biochem. (Tokyo) 129, 653-664.
Strobl, S., Fernandez-Catalan, C., Braun, M., Huber, R., Masumoto, H., Nakagawa, K., Irie, A., Sorimachi, H., Bourenkow, G., Bartunik, H., et al. (2000). The crystal structure of calcium-free human $\mathrm{m}$-calpain suggests an electrostatic switch mechanism for activation by calcium. Proc. Natl. Acad. Sci. USA 97, 588-592.

Takano, E., Ma, H., Yang, H.Q., Maki, M., and Hatanaka, M. (1995). Preference of calcium-dependent interactions between calmodulin-like domains of calpain and calpastatin subdomains. FEBS Lett. 362, 93-97.

Teixido, M., Altamura, M., Quartara, L., Giolitti, A., Maggi, C.A., Giralt, E., and Albericio, F. (2003). Bicyclic homodetic peptide libraries: comparison of synthetic strategies for their solidphase synthesis. J. Comb. Chem. 5, 760-768.

Todd, B., Moore, D., Deivanayagam, C.C.S., Lin, G., Chattopadhyay, D., Maki, M., Wang, K.K.W., and Narayana, S.V.L. (2003). A structural model for the inhibition of calpain by calpastatin: crystal structures of the native domain VI of calpain and its complexes with calpastatin peptide and a small molecule inhibitor. J. Mol. Biol. 328, 131-146.

Tompa, P. (2002). Intrinsically unstructured proteins. Trends Biochem. Sci. 27, 527-533.

Tompa, P., Mucsi, Z., Orosz, G., and Friedrich, P. (2002). Calpastatin subdomains $A$ and $C$ are activators of calpain. J. Biol. Chem. 277, 9022-9026.

Uemori, T., Shimojo, T., Asada, K., Asano, T., Kimizuka, F., Kato, I., Maki, M., Hatanaka, M., Murachi, T., Hanzawa, H., et al. (1990). Characterization of a functional domain of human calpastatin. Biochem. Biophys. Res. Commun. 166, 1485-1493.

Uversky, V.N. (2002). Natively unfolded proteins: a point where biology waits for physics. Protein Sci. 11, 739-756.

Wells, G.J. and Bihovsky, R. (1998). Calpain inhibitors as potential treatment for stroke and other neurodegenerative diseases: recent trends and developments. Exp. Opin. Ther. Patents 8, 1707-1727.

Wendt, A., Thompson, V.F., and Goll, D.E. (2004). Interaction of calpastatin with calpain: a review. Biol. Chem. 385, 465-472.

Received March 29, 2007; accepted September 12, 2007 